\title{
Rejuvenating and Facilitating Second Language Teaching Process With Activities and Games
}

\author{
LIU Xu-liang \\ China Youth University of Political Studies, Beijing, China
}

\begin{abstract}
Second language teachers are often impressed that activities and games are always enjoyed by students of different levels. When some novel and original activities and games are conducted in the classroom, students would participate in with great interest and enthusiasm, and often yield unexpected teaching results. Despite the usefulness and significance, its role has long been despised and marginalized. This article is intended to reexamine its role and status in language teaching and make them serve the teaching objectives the best.
\end{abstract}

Keywords: activities and games, diversity, flexibility

\section{Introduction}

Teaching activities and games are an integral part of second language education. A well-prepared and conducted teaching activity or game can greatly facilitate the completion of teaching tasks, and plays an indispensable role in the expanding and deepening of the teaching content. However, its important status has long been neglected and despised, and not duly embodied in the traditional teaching syllabus and curriculum. Many teachers have misunderstandings of teaching activities and games, simply regarding them as leisure and entertainment after regular teaching, consequently constrain them only towards the end of a class or semester as supplementary fillers and relaxations.

\section{The Relationship Between Teaching Activity and Game}

Teaching activities and games are of logical containment relationship which has both connection and difference. Game is a part of teaching activity, but not all teaching activities can be called a game, especially for adult learners. Their sameness lies in the shared goal to stimulate students' learning enthusiasm and motivation to improve the second language competence through meaningful steps and procedures. Their difference is also manifest. Besides the entertaining effect and relaxing experience, games lay more emphasis on the individual performance and achievement. While teaching activity is often geared to the needs of overall students, taking account of most of the students' proficiency, therefore attaches more importance to team work, cooperation, management, and control. In addition, teaching activity is usually free of competition, thus does not highlight the importance of winning or losing. So long as students manage to live up with teachers' requirements with due efforts, their performance would be credited. In contrast, games are more competitive in nature. To achieve the goal, students must devote great efforts, and experience series of accomplishment or loss in the battle, which are conducive to the building of strong self-confidence and help to lay a solid foundation

LIU Xu-liang, lecturer, master, Foreign Language Department, China Youth University of Political Studies. 
for the automation of second language lifelong learning.

\section{The Vital Importance of Activities and Games}

\section{Needs of Class Liveliness and Diversity}

For a long time, college English teaching has long been despised with its high input and low output. The deaf and mute phenomenon is rampant and widespread. To probe into the reason, both of the education system and teaching method should be held accountable. Traditionally, English as a second language is imparted and learned primarily as a department of rigid and closed knowledge in college classroom, which is far deviated from its essence as a tool of communication. Over time, students' communicative competence is not trained and promoted in the real sense, causing the overall failure of language teaching. College English syllabus has recently stated clearly to develop the students' communicative ability as the main target. Language learning should be oriented to skill improving and building as in driving, if a driver only confines to the classroom to learn the traffic rules and driving operations, and not drive on the real road, then to become a qualified driver would become a castle in the air. In traditional classroom, the teacher's role is usually to explain and expound the language points of the textbooks, with which students' interest and motivation are not fully mobilized due to the boring grammar and rote vocabulary learning. On the other hand, students now have instant access to wide range of information, including the teaching materials and book translations, rendering the teachers' interpretation redundant and burdensome. In view of this, the rise of communicative teaching method in recent years is expected to make some changes, but due to the lack of specific framework and applicable method design, it failed to impose a real shock on the traditional translation teaching method. Also in recent years the rise of the task-based and content based teaching approach can be viewed as the development and evolution of communicative teaching method, but because the teaching material are too little and insufficient to effectively support the theory, they are basically kept in the stage of discussion and validation. Based on the above, the author puts forward activity teaching method, which can be taken as a combination of the above methods. The difference is that the former has more practicability and maneuverability, and can effectively make up for the inadequacy of the above ways.

\section{The Need to Alleviate the Learning Pressure}

Hadfield (1990) proposed activities and games should be taken as an organic part of the language teaching outline. The language learning process is always full of difficulties and challenges, learners to understand, master, and use a second language usually take hardship and effort. Entertaining games and activities can make the teaching process an amusing and relaxing one. Students' learning stress will be greatly relieved in a real-world scenario of meaningful language use, which is phenomenally conducive to the improvement of language competence. And because the games are often challenging and competitive in nature, they can greatly stimulate the learning enthusiasm and motivation of participation, thus is favorable to the realization of teaching goals. Schultz (1988) even thinks pressure is the biggest barrier for students in learning a language. Students can forget they are learning when doing activities and games so as to minimize stress and anxiety to the greatest degree, which helps to build natural expression and communication. In a word, teaching activities and games can help students achieve the unconscious and automatic study.

\section{When to Use Activities and Games}

Activities and games are not necessarily used as a warming-up activity (appetizer) or time filler by the end 
of a lesson. Just as lee (1979) said, "a game should not be seen as a marginal activity filling in irregular moment teacher and class don't have better things to do" (p. 3). Rixon even suggests that activities and games could be the core of foreign language teaching and can be used in all stages of the lesson, on condition that they are well planned and carefully chosen. Therefore, teaching activities and games are not necessarily conducted as supplementary activities, but a necessary tool in the implementation and the realization of the syllabus. Their roles can be never too exaggerated so long as they can facilitate the acquiring process, motivate the learners, and promote the communication accuracy and fluency.

\section{Diversity and Flexibility of Activities and Games}

According to different criteria, activity can be classified into different types and categories. Length of the process: real-time (temporary), short-term, medium-term, and long-term. Notion and skills: vocabulary, grammar, reading, speaking, writing activities, etc. Form of the activity: role plays, debates, discussions, interviews, questionnaires, dubbing... Apart from these usual ones, activities and games can be further divided according to its property, function and membership.

\section{Eye-Catching and Inspiring Activities}

A proper activity can grab the attention of students and can have the twice effect with half effort. According to cognitive psychology, short-term memory must go through the process of noticing in language processing before it eventually becomes long-term memory. So what kind of language materials and activities are easy to be noticed? In general, they should satisfy the following conditions: (1) the refreshing ones which are easy to pose impact on people's visual and audial sense, hence, focused image, distinctive voice and the novel topic and content can often hold the students' attention in the first time; (2) agree with the others' own content. Topics like: should Beijing University recruit more recommended students? Should we help the elderly fell down? These topics are usually in percussion with the students' thinking; and (3) something of personal interests and looking forward to. Jobes, for example, is many youngsters' idol, whose personal achievements and legendary life have great fascinations to many young people, therefore, Jobes related topics of reading, discussion, and listening activities can greatly satisfy the curiosity of students, naturally will attract students' interests and attention. Therefore, the teacher in the designing and inserting of activities and games in class should take account of the above three factors to achieve the desired effect. A good beginning is half done. Teachers' meticulously prepared and designed activity can catch the students' attention in the first time and lead them to the desired knowledge through reasonable and scientific steps, making the knowledge and content to be acquired naturally and unconsciously. In fact, the students' attention is easy to be distracted by various factors, in addition to language factors as the complex syntax and unfamiliar vocabulary, psychologists after a study found that young people's attention is of fatigue cycles of 15 minutes. On average, every 15 minutes attention is experiencing a fatigue period. If a learning and instruction process proceeds more than 15 minutes and without a pause and rest, students' attention will disperse and transfer. So the experienced teachers when designing and implementing teaching activities should follow the students' attention cycle, making the student's attention back to the topic again after a short rest immediately, so as to complete the learning and instruction process. Alleviating attention fatigue method is to ask questions, to tell jokes, play games, etc.

\section{Summing-Up and Inspection Activities}

At the end of a semester, it is necessary for the teacher to lead the students to review important and classic 
sentences learned in the semester with a view to enhance their impression and retention.

Race to locate classic sentences: Teacher reads a sentence; students quickly find and tell the corresponding unit and the paragraph, and the first student telling the specific location makes a score. Then teacher reads the second sentence, the third sentence... five to six sentences for each unit, and each one is either rich in content or novel and classic in choice of words and patterns. These sentences can usually serve as models of writing and translation.

\section{Individual and Group Activities}

Individual shows. Individual activities include English singing, poetry reading, storytelling, film dubbing, magic show, news broadcast, etc. Talent show scoring elements include: clear form and theme, explicit description and presentation, proper and articulate English, creativity and originality, and interaction with the audience or class.

English news report: listen to a piece of English news and then retell the story to the class or act as a news reporter to live broadcast the news after preparation.

Poker magic: The magician first introduces the name of cards and what JQK stand for. E.g., the four images of Poker are called spade, heart, club, and diamond. JOK stand for Jack, Queen, and King. Then introduce the rules of magic and act in steps to achieve the desired effect and results. Performer in the process uses English to communicate with the audience and invite the audience to join the play at times.

Group work (two or multiplayers in the group). A two-man comic show: One student acts in the front, and the other speaks or sings hiding behind. The two people works together to complete the performance.

An interview of a VIP: One student acts as the journalist, and the other as a very famous film star, great athlete, or distinguished professor or scholar. They hold a dialogue with questions and answers.

To role play the Western wedding ceremony in groups. Member students play the groom and bride, best man and maid of honor, parents of both sides, priests, and guests, etc. In order to help students better prepare for group shows, teachers may firstly play the video clips of wedding process and display the text scripts if necessary, helping the students understand the dialogue happens in the process of the wedding, and at the same time providing more useful language stuff such as vows for ceremony.

In most cases, the implementation of one activity or game involves both individual and teamwork, with mutual transformations during the process among individual activities, group activities, and class activities. Just take "introduction in the first class" as an example: Students firstly introduce themselves among groups. Contents may cover: (1) your name and your hometown; (2) your idol or a role model; (3) your impression of the university and of the city; and (4) your major and expectation of college life. Then the spokesperson introduces the group members to the class.

Teaching activity is determined by and caters to teaching objectives and purposes, and it is often the case that one activity is not always serving a single teaching purpose, but multiple purposes and forms a combination.

\section{Problems That Should Be Mindful When Implementing Activities and Games}

In the process of activities, teachers are not supposed to interrupt and have error correction with the students so frequently and willfully. Exceptions are admitted. Students who are reluctant to participate in activities may be of multiple reasons, and forcing them to participate usually does not produce the desired 
effect, therefore, is not suggested. In choosing and designing activities, teachers should give full concern to the characteristics and levels of all the target students, and make due adjustments to the games to render them suitable and applicable. The game descriptions and the directions should be manifest, which guarantee the students will follow the rules and steps and accomplish the tasks as required and desired. Teachers should also give full play to the role of modern latest technology in the implementation of activities and games. A comprehensive knowledge and mastery of the latest technology such as short message, QQ, Wechat, E-community, etc., is not only a necessity in modern language education, but also an indispensable professional skill for language teachers. Teachers should take a lead in the application and instruction of the great functions of certain techniques and apps, and recommend them to students on a regular basis when arranging teaching tasks and assignments. These new techniques can greatly change the monotonous teaching model as a whole, making the process more dynamic and greatly extended in dimension.

\section{Conclusion}

Activities and games have great advantages in relieving anxiety, arousing motivation, creating trust environment, and building confidence in learning a language well. A well-planned and meticulously organized and conducted teaching activity can greatly change the teaching dynamics and ecology and promote the implementation of the teaching tasks. Currently, Effective and well-designed activities are generally not very accessible, and to design an original and productive teaching activity usually involves a large amount of time and energy payment for teachers. As a result, teachers are reluctant to integrate activities in overall teaching curriculum. Therefore, to help teachers develop a multitude of accessible and applicable teaching activities and games is becoming increasing important and urgent.

\section{References}

Deesria, A. (2000). Games in the ESL and EFL class. The Internet TESL Journal, VI(6), 16.

Hadfield, J. (1990). Intermediate communication games. In An collection of games and activities for low to mid-intermediate students of English. Hong Kong: Thomus and Nelson and Nelson and Sons Ltd..

Lee, S. K. (1995). Creative games for the language class. Forum, 33(1), 35.

Schultz, M., \& Fisher, A. (1988). Games for all reasons: Interacting in the language classroom. Massachusetts: Addison-Wesley Publishing.

Shelagh, R. (1981). How to use games in language teaching (p. 46). London: Macmillan Publishers.

Uberman, A. (1998). The use of games for vocabulary presentation and revision. English Forum, 36(1), 20. 